\title{
Review on Application of Aluminum Foam in Sound Absorption Technology
}

\author{
Shashikant V. Raut ${ }^{+*}$, V. S. Kanthale ${ }^{\dagger}$ and B. S. Kothavale ${ }^{\dagger}$ \\ ${ }^{\dagger}$ Mechanical Department, MIT Collage of Engg, SSPU Pune, ndia \\ Accepted 03 March 2016, Available online 15 March 2016, Special Issue-4 (March 2016)
}

\begin{abstract}
This paper presents the study of review of aluminum foam application in sound absorption technology fabrication method, properties and application of aluminum foam discus in studies. The Open and semi-opened aluminum foams are good sound absorbers and closed-cell aluminum foams are poor sound absorbers. Closed-cell aluminum foams can have good sound absorption capacity after some processes such as hole drilling, rolling and compression. The foam thickness increased then the sound absorption peak appeared at low frequency is shifted towards lower frequencies as the sample thickness increased. The sound absorption capacity also depends on pore size and pore opening size. The pore opening size decreasing the height of low-frequency peak shifted towards lower frequencies. The increasing the pore size with the height of low-frequency peak increased.
\end{abstract}

Keywords: sound absorption technology, aluminium foam.

\section{Introduction}

Foams are the result of a two phase combination created by various processes most of which include the dispersion of a gas through a liquid without dissolving the gas completely. This is very similar to the emulsion process (combination of two immiscible liquids) but having the difference that a gas phase must exist in the foam. Metal foam is a cellular structure consisting of a solid metal, frequently aluminium, as well as a large volume fraction of gas-filled pores. The pores can be sealed (closed-cell foam), or they can form an interconnected network (open-cell foam). Applications of al metal foam are Structural Applications, Heat Exchangers and Cooling Machines, Silencers, Acoustic Applications, Flame Arresters, Corrosion-resistant Applications. Metallic foams typically retain some physical properties of their base material. Foam made from non-flammable metal will remain non-flammable and the foam is generally recyclable back to its base material. Coefficient of thermal expansion will also remain similar while thermal conductivity will likely be reduced.

The sound absorption behaviour was examined and correlated with the air flow resistance for the aluminium foams with controllable sizes of both pores and pore openings in the present study. The aluminium foam samples were produced by an air pressure infiltration process using spherical sodium chloride $(\mathrm{NaCl})$ particles as the space holder material that was

*Corresponding author: Shashikant V. Raut prepared by sintering the $\mathrm{NaCl}$ powders. The paper presents new method for production of closed-cell $\mathrm{Al}$ foams of improved sound absorbing ability with no machining operations. Opening the closed-cell structure of solid foamed $\mathrm{Al}$ is provided by micrometer sized cracks lengthways the eutectic domains created by finish heat treatment that includes heating below the solidus temperature followed by water quenching.

Al-Si closed-cell aluminum foam sandwich panels $(1240 \mathrm{~mm} \cdot 1100 \mathrm{~mm})$ of different thicknesses and different densities were prepared by molten body transitional foaming process in North-eastern University. The experiments were carried out to investigate the sound insulation property of $\mathrm{Al}-\mathrm{Si}$ closed-cell aluminum foam sandwich panels of different thicknesses and different densities under different frequencies.

The damping and sound absorption properties of A356/xSiCp composite foams have been studied (xexpresses Sic vol. \%). The results show that the loss factor _ of A356/SiCp foams changes slightly with the increasing of temperature and frequency within the measured range.

A novel sort of cellular titanium foam, whose total porosity was achieved as high as $86 \%-90 \%$ and main pores were spherically millimeter-scaled, was recently prepared successfully by an improved foaming method of melting the metallic powder. This titanium foam showed a good performance of sound absorption, and its sound absorption coefficient could be more than 0.6 in the sound-wave frequency range of $3150-6300 \mathrm{~Hz}$ and even exceed 0.9 at the resonance frequency. 
The sound absorption behaviour of the open-celled $\mathrm{Al}$ foams manufactured by the infiltration process, and the mechanisms involved. The foams show a significant improvement in sound absorption compared with close-celled $\mathrm{Al}$ foams, because of their high flow resistance.

A methodology is proposed for designing porous fibrous material with optimal sound absorption under set frequency bands. The material is assumed to have a rigid frame and a hexagonal arrangement of fibres.

The studies investigate the compressive behavior of aluminum composite. The results show that the quasistatic stress-strain $(\sigma-\varepsilon)$ curves of the $\mathrm{Al}$ composite were similar to that of $\mathrm{Al}$ foams. The ideal energy absorption efficiency of the composites was higher than those of $\mathrm{Al}$ foams.

AFS panels are new class of flat structures, of two aluminum layers with core made by foamed aluminum. Their better combination of properties, arising from the metallic nature of the matrix and from the porosity behavior of the foam core, guarantees high specific stiffness, thermal and acoustical isolation and vibration damping.

The Aluminum foams produced by powder metallurgical route present an initial anisotropicsemisolid expansion that detrimental effect on the foam ability and the subsequent quality of the final cellular structure. It is based on use of heat treatments below the solidus temperature, and has been tested in AlSi10 (0.8 wt. \%TiH2).

\section{Aluminum metal foam}

Metal foams became an attractive research field both from the scientific and industrial applications points of view. The Closed-cell metal foams of particular aluminum alloy (Al-alloy) ones can be used as lightweight, energy-absorption and damping structures in different industrial sectors. Al-alloys are low density, high ductility, high thermal conductivity and competitive cost. Metallic foams of aluminum, offer a great potential for applications in the automotive industry. Foams are light weight, energy absorbing and incombustible and have good sound absorbing properties. Other applications are engineering, building, household goods and the chemical industry.

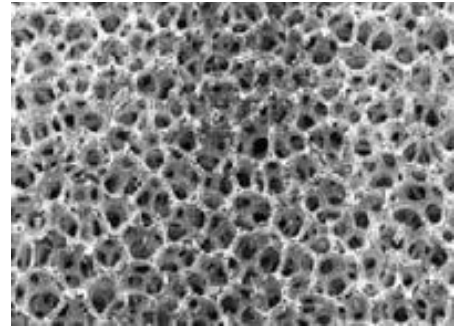

Fig .1 Metal foam

A foaming agent is a material that facilitates formation of foam such as a surfactant or a blowing agent. A surfactant, when present in small amounts, reduces surface tension of a liquid. A blowing agent is a gas that forms the gaseous part of the foam. There are two main types of blowing agents: gases at the temperature that the foam is formed, and gasses generated by chemical reaction. Blowing agents that produce gas via chemical reactions include baking powder, azodicarbonamide, titanium hydride, and andisocyanates.

\section{Properties}

Aluminium foams are isotropic porous materials with several unusually properties that make them especially suited for some applications. Due to their low densities between $0.3 \mathrm{~g} / \mathrm{cm} 3$ and $0.8 \mathrm{~g} / \mathrm{cm} 3$ the foams can float in water. Foams exhibit a reduced conductivity for both heat and electricity. The strength is lower than conventional dense aluminium and declines with decreasing density. Foams are stable at temperatures up to the melting point. They are incombustible and non-toxic. In most foam production technologies the properties can be varied over a wide range by controlling the production parameters. Due to their cellular structure foams behave differently in testing when compared to conventional metal. Therefore conventional testing methods cannot be used, for example tensile testing.

\section{Fabrication method}

During the last ten years technologies has been developed for the production of metallic foams or similar porous metal structures. It has to be stressed to be mentioned that only some of these processes will be suited for the production of aluminium foams. The basically technologies can be divided into those that start with the liquid metal or with a metal powder.

\subsection{Foams made from metallic melts (LM foams)}

All these methods start with the melting of the metal that will be foamed.

\section{a) Foaming Melts by Gas Injection}

The first manufacturing method of foaming aluminum and aluminum alloy melts is based on gas injection.

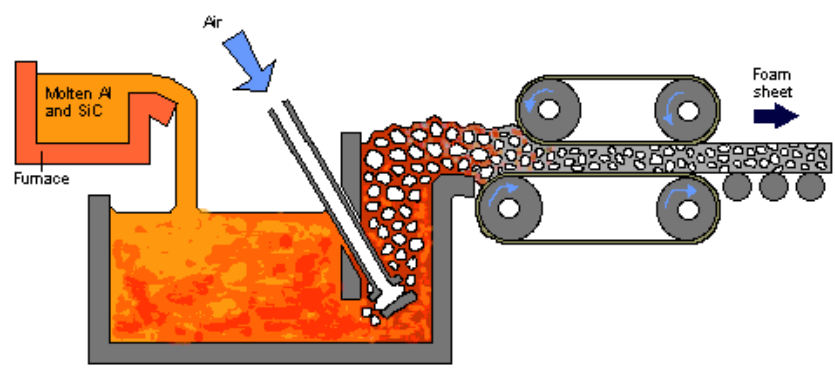

Fig.2 Schematic diagram of manufacturing of aluminium foam by melt gas injection method. (Source: WEB_1, 2005)

In this process, Sic, aluminum oxide or magnesium oxide particles are used to the liquid metal and adjust 
its foaming properties because liquid metals cannot easily be foamed by bubbling air through. The method is shown schematically in Figure 2. The volume fraction of particles varies from $10 \%$ to $20 \%$, and the mean size of the particles range $5 \mu \mathrm{m}$ and $20 \mu \mathrm{m}$. In this process the production of closed-cell foams of $1 \mathrm{~m}$ wide to $0.2 \mathrm{~m}$ thick slabs with diameters rang $5 \mathrm{~mm}$ and $20 \mathrm{~mm}$ and the foam relative densities between 0.03-0.1.

\section{b) Foaming Melts with Blowing Agents}

In this method add blowing agent into the melt. The blowing agent decomposes under influence of heat and releases gas. The method is shown schematically in Figure 3 . The first stage of the foam production about $1.5 \mathrm{wt}$ \% calcium metals adds to the aluminum melt at $680{ }^{\circ} \mathrm{C}$. Titanium hydride is add in an amount typically $1.6 \mathrm{wt}$ \%. The blowing agent according to the following reaction:

$$
\mathrm{TiH} 2(\mathrm{~s}) \rightarrow \mathrm{Ti}(\mathrm{s})+\mathrm{H} 2(\mathrm{~g})
$$

The melt starts to expand slowly and suddenly fills the foaming vessel. The foaming process can take $15 \mathrm{~min}$. cooling the vessel below the melting point of the alloy, the liquid foam turns into solid aluminum foam.

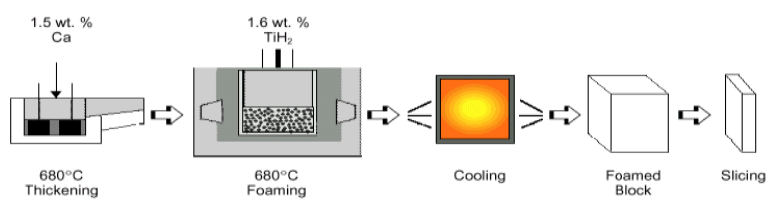

Fig.3 The process steps of aluminium foam forming by gas releasing agent, Alporas process. (Source: Banhart 2000a)

\subsection{Foams made from metal powders (PM foams)}

The process starts with the mixing of metal powders, alloy powders and metal powder blends with a powdered blowing agent.

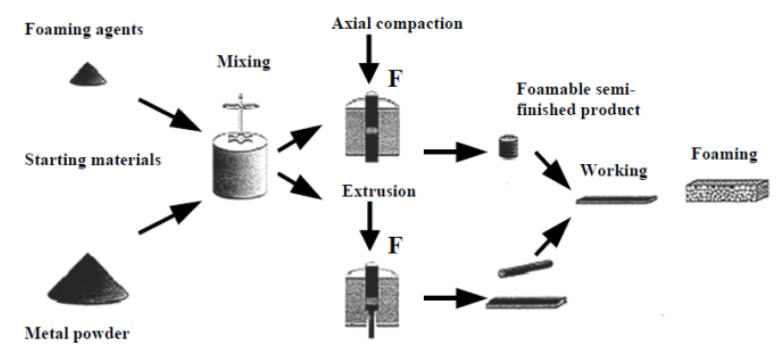

Fig.4 Foaming from powder compacts process. (Source: Baumgärtner et al. 2000)

The Foaming agent decomposes and the material expands by released gas forces in heating process (350 oC- $450 \mathrm{oC}$ ) thus a highly porous structure is formed. The mixture of powders, metal powder and foaming agent, is cold compacted to give solid metal material containing a dispersion of powdered foaming agent. When this solid was heated to the metal melting temperature, the foaming agent decomposes release gas into the molten metal and creates the foam. The method is shown schematically in Figure 4.

\section{Sound Absorption}

The sound travels through a medium; its intensity varies with distance. The sound pressure is reduced by the spreading of the wave. The combined effect of scattering and absorption is called attenuation (Brown 2000). The combination of fluctuations in pressure and velocity can be used to form a measure of sound power. Sound-absorbing materials such as absorbent ceiling panels, carpeting on the floor, and drapes or special absorbent wall coverings, are commonly used in industry to reduce noise for which the sound waves are reflected, absorbed and transmitted when they hit a hard surface (Figure 5).

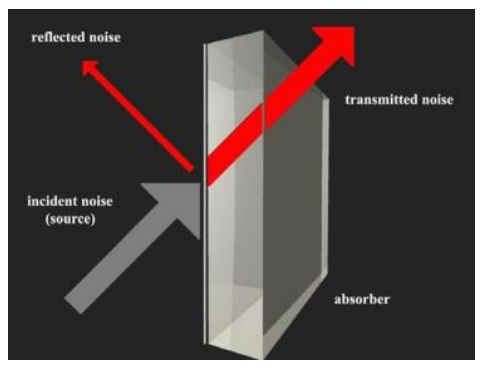

Fig.5 Sound absorption and reflection of a material

The sound absorption coefficient is a measure of the proportion of the sound striking a surface, which is absorbed by that surface, and is usually given for a particular frequency. Thus, a surface which would absorb $100 \%$ of the incident sound would have a sound absorption coefficient of 1.00. The sound absorption coefficients of commonly used materials are listed in table 5.2 (Brown 2000).

Table.1 Sound absorption coefficient of some selected materials measured at $500 \mathrm{~Hz}$ (Source: Brown 2000)

\begin{tabular}{|c|c|}
\hline Material & $\begin{array}{c}\text { Sound absorption } \\
\text { coefficient, }(\boldsymbol{\alpha})\end{array}$ \\
\hline Plaster walls & $0.01-0.03$ \\
\hline Unpainted brickwork & $0.02-0.05$ \\
\hline Painted brickwork & $0.01-0.02$ \\
\hline 3 mm plywood panel & $0.01-0.02$ \\
\hline $6 \mathrm{~mm}$ porous rubber sheet & $0.1-0.2$ \\
\hline $12 \mathrm{~mm}$ fibreboard on battens & $0.3-0.4$ \\
\hline $\begin{array}{c}25 \mathrm{~mm} \text { wood wool cement } \\
\text { on battens }\end{array}$ & $0.6-0.07$ \\
\hline $50 \mathrm{~mm}$ slag wool or glass silk & $0.8-0.9$ \\
\hline Hardwood & 0.3 \\
\hline
\end{tabular}

\section{Application}

Metallic foams are the combinations of unique physicochemical as well as mechanical properties. The 
aluminum metal foam used in many applications such as structural applications, energy absorption of Impacts and explosions, sound absorption technology, heat exchanger and cooling process, Silencers, Acoustic Applications, Flame Arresters, Energy Absorption Applications, Corrosion-resistant Applications, Automotive Applications. An application area of cellular metals, grouped according to the degree of openness is shown in below fig.5. Al foams also used in a wide variety of noise control treatments like machinery enclosures, plant machinery, walls, in automobiles for engine, tire, door noise and sides of roads to reduce traffic noise.

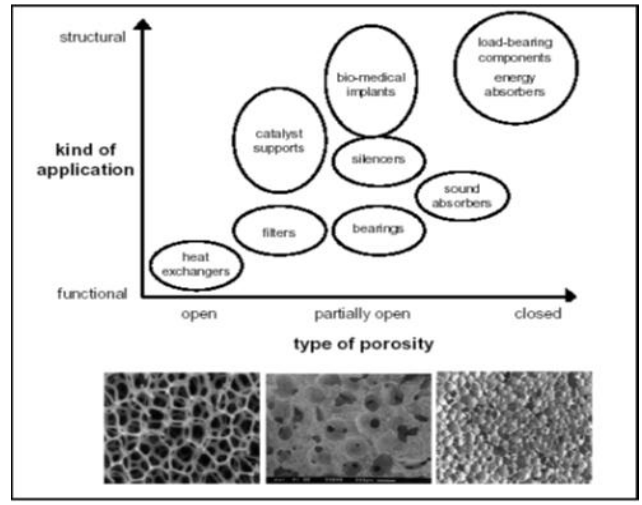

Fig.5Application areas of cellular metals, grouped according to the degree of openness. (Source: Banhart 2003)

\section{Acoustic Applications}

Closed-cell Aluminum foams are poor sound absorbers and the opened aluminum foams are good sound absorbers and they are used for noise reduction. Closed-cell aluminum foams can have good sound absorption capacity after some processes such as drilling and rolling. Sound absorption materials control airborne noise by reducing reflection of sound from the surface boundaries then reducing the overall noise levels. . The damping capacity of aluminium foam is to be an order of magnitude higher than that of the bulk metal.

\section{Silencers}

Components for dampening of sound, of mechanical vibrations are also common in industrial applications of powder metallurgy. Materials With open porosity can be tailored to damp some frequencies selectively while they allow passing others. Sudden pressure changes occurring, e.g. in compressors or pneumatic devices can be damped with foams. Materials such as the investment cast foams or the foams made by deposition could replace such traditional elements for reasons of cost and affectivity.

\section{Results}

The sound absorption coefficient vs. frequency in varied sample thicknesses is shown in Figure 6. It is seen that the sound absorption coefficient changes with frequency. Sound absorption peak appeared at low frequency is shifted towards lower frequencies as the sample thickness increased.

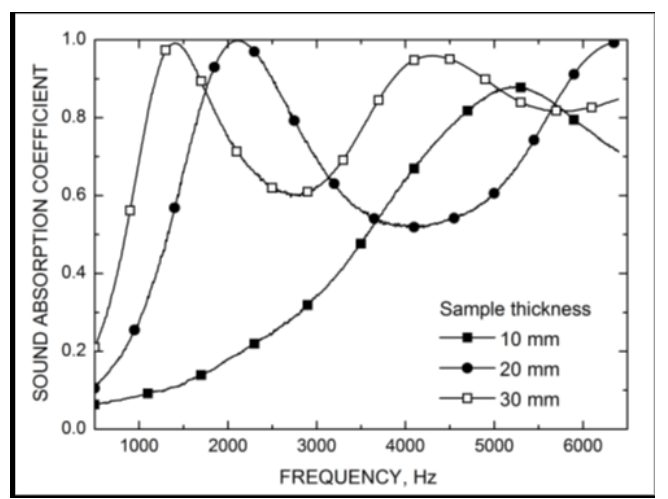

Fig.6 sound absorption coefficient vs. frequency for the sample thickness

The height of low-frequency peak increased with increasing the pore opening size, when the location shifted towards lower frequencies with decreasing the pore opening size sample $(0.26,0.31$, and 0.36$)$.

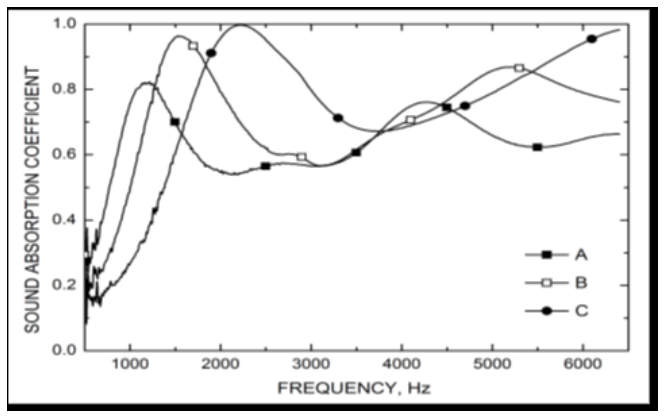

Fig. 7 Sound absorption coefficient vs. frequency for the samples with varied pore opening sizes

\section{References}

Junkie Li, 2014, Air flow resistance and sound absorption behaviour of opencelled aluminium foams with spherical cells, Procedia Materials Science 4 (2014) 187 - 190. Alexandra Byakova, (2014), Fabrication method for closed-cell aluminium foam with improved sound absorption ability, Procedia Materials Science 4 (2014) $13-18$

Haijun $\mathrm{Yu},(2007)$, Sound insulation property of Al-Si closed-cell aluminium foam sandwich panels, Applied Acoustics 68 (2007) 1502-1510.

Wu Jiejun, (2003), Damping and sound absorption properties of particle reinforced $\mathrm{Al}$ matrix composite foams, Composites Science and Technology 63 (2003) 569-574

P.S. Liu, (2015), Primary investigation on sound absorption performance of highly porous titanium foams, Materials and Design 85 (2015) 275-281.

Fusheng Han, (2003), Acoustic absorption behavior of open-celled aluminum foam, Appl. Phys. 36 (2003) 294-302.

Shutian Liu, (2014), Design optimization of porous fibrous material for maximizing absorption of sounds under set frequency bands, Applied Acoustics 76 (2014) 319-328.

Yong-gang Li, (2015), Fabrication and compressive behaviour of an aluminium foam composite, Journal of Alloys and Compounds (2015).

Giuseppe Petrone, (2014), Numerical and experimental investigations on the acoustic power radiated by Aluminium Foam Sandwich panels, Composite Structures 118 (2014) 170-177.

Jaime Lázar, (2014), Heat treatment of aluminium foam precursors: effects on foam expansion and final cellular structure, Procedia Materials Science 4 (2014) 287 - 292. 